\title{
Model Sumur Resapan dan Drainase Untuk Penanggulangan Banjir Dengan Memanfaatkan Material Lokal
}

\author{
Yuliyanti Kadir ${ }^{1}$, Indriati Martha Patuti ${ }^{2}$, Frice L. Desei ${ }^{3}$ \\ 1,2,3 Jurusan Teknik Sipil, Fakultas Teknik, Universitas Negeri Gorontalo \\ Email : yuliyanti_kadir@ung.ac.id ${ }^{1}$, indri.m.patuti@ung.ac.id ${ }^{2}$, \\ fricedesei@yahoo.com ${ }^{3}$
}

\begin{abstract}
ABSTRAK
Banjir adalah suatu bencana yang sering terjadi pada musim penghujan. Kerusakan yang ditimbulkan oleh bencana ini tidak hanya berupa kerusakan materi seperti kerusakan rumah penduduk, fasilitas umum, dan rusaknya lahan pertanian, tetapi juga menimbulkan wabah penyakit di sekitar lokasi bencana. Salah satu solusi untuk mengurangi limpasan air hujan, perlu dibuatkan model sumur resapan yang mudah dan praktis dengan memanfaatkan material lokal.Tujuan dari penelitian ini adalah pemodelan sumur resapan dan drainase untuk pencegahan dan penanggulangan bahaya banjir agar tercapai suatu kondisi lingkungan yang sehat, aman, dan nyaman. Lokasi penelitian adalah Desa Lauwonu, Kecamatan Tilango, Kabupaten Gorontalo. Bahan konstruksi untuk pembuatan model adalah material lokal yang berada di sekitar lokasi. Sumur resapan yang dibuat berukuran $(2 \times 1 \times 1) \mathrm{m}^{3}$ dan $(2 \times 1,5 \times 1) \mathrm{m}^{3}$. Apabila setiap rumah tangga memiliki 1 buah sumur resapan dengan minimal volume $2 \mathrm{~m}^{3}$, maka akan mengurangi limpasan air hujan, sehingga bencana banjir dapat dihindari.
\end{abstract}

Kata kunci: sumur resapan, drainase, banjir, material lokal

\section{ABSTRACT}

Flooding is a disaster that often occurs in the rainy season. The damage caused by this failure is not only material damage such as damage to houses, public facilities, and destruction of agricultural land, but also create disease outbreaks around the disaster site. One solution to reduce rainwater runoff needs to be made easy and practical recharge well model by utilizing local materials. The purpose of this research is the modeling of absorbing wells and drainage for prevention and control of flood hazard to achieve a healthy, safe, and comfortable. The research location is Lauwonu Village, Tilango District, Gorontalo Regency. Construction materials for modeling are local materials located around the site. The recharge wells are sized $(2 \times 1 \times 1) \mathrm{m}^{3}$ and $(2 \times 1,5 \times 1) \mathrm{m}^{3}$. If every household has a recharge well with a minimum volume of $2 \mathrm{~m}^{3}$, it will reduce rainfall runoff so that that flood disaster can be avoided.

Key Word: absorption wells; drainage; floods; local materials.

\section{PENDAHULUAN}

Sumur resapan air hujan adalah sarana untuk menampung air hujan dan meresapkannya ke dalam tanah, baik berupa sumur, parit atau alur taman resapan. Selain itu sumur resapan berguna sebagai salah satu cara dalam meningkatkan volume air tanah dan upaya penanggulangan dampak bencana alam kekeringan (Badan Standardisasi Nasional, 2002). Sumur resapan efektif untuk digunakan karena sebagai pengendali banjir dan genangan, sumur resapan 
mampu meresapkan air hujan yang melimpah dan berguna pula untuk konservasi air tanah serta menekan laju erosi (Wahyuningtyas, et al., 2011). Pembangunan sumur resapan harus dibarengi dengan pembangunan drainase, sehingga bencana banjir dapat diatasi. Drainase mempunyai arti mengeringkan atau mengalirkan. Drainase merupakan sebuah sistem yang dibuat untuk menangani persoalan kelebihan air baik kelebihan air yang berada di atas permukan tanah maupun air yang berada di bawah permukaan tanah. Kelebihan air disebabkan oleh intensitas hujan yang tinggi ataupun akibat durasi hujan yang lama (Wesli, 2008). Dewi, et al., 2014 menyatakan bahwa drainase merupakan sarana atau prasarana untuk mengalirkan air hujan dari suatu tempat ke tempat yang lain.

Desa Lauwonu adalah salah satu desa di Kecamatan Tilango, Kabupaten Gorontalo yang terletak di daerah dataran rendah dengan luas sebesar 3,57 $\mathrm{km}^{2}$. Pada tahun 2014, jumlah penduduk Desa Lauwonu adalah sebesar 1.682 jiwa (410 KK, dengan rata-rata anggota keluarga sebanyak 4 orang). (BPS Kabupaten Gorontalo, 2015). Desa Lauwonu terdiri dari tiga dusun, yaitu Dusun I, II, dan III. Desa ini sering dilanda banjir pada saat musim penghujan. Hal ini diakibatkan karena sistem drainase yang tidak berfungsi sebagaimana mestinya, sehingga aliran air dari limbah rumah tangga dan aliran air hujan tidak mengalir dengan baik. Tidak adanya saluran drainase pinggir jalan serta tidak adanya sumur resapan untuk air limbah rumah tangga sehingga pada waktu musim hujan, terjadi banjir. Kejadian banjir ini sudah terjadi bertahun-tahun, dan hal ini menjadi bencana rutin yang dialami masyarakat di Desa Lauwonu setiap musim penghujan. Bencana ini selain menimbulkan kerusakan rumah penduduk dan sarana jalan serta fasilitas umum lain di lingkungan ini, juga menimbulkan penyebaran wabah penyakit seperti diare, demam, ISPA, penyakit kulit, dan lain-lain. Salah satu solusi untuk penanggulangan banjir, perlu dibuatkan model sumur resapan dan drainase dengan memanfaatkan material lokal, yang dilakukan dengan teknologi yang mudah, ekonomis, dan praktis berdasar kajian ilmiah.

Sumur resapan dibuat dengan memanfaatkan material lokal, yaitu dilapisi dengan ijuk sebagai media filter dan diurug dengan batu kapur. Air hujan yang masuk ke dalam sumur resapan tidak meresap ke samping (luar dinding), melainkan dapat seluruhnya meresap ke dasar tanah dan dapat ditampung seoptimal mungkin. Letak sumur resapan sebaiknya berjauhan dengan septic tank maupun sumur gali (Indramaya \& Purnama, 2013). Kondisi ini sebagaimana tercantum pada Standar Nasioanl Indonesia (SNI) Nomor 032453-2002, yang menentukan jarak antara sumur resapan dan septic tank minimal 5 meter. Jarak antara sumur 
Yuliyanti Kadir ${ }^{1}$, Indriati Martha Patuti ${ }^{2}$, Frice L. Desei ${ }^{3}$ /

Aksiologiya: Jurnal Pengabdian Kepada Masyarakat. Vol.1, No.2, Agustus 2017 Hal $92-96$

resapan dan sumur gali berjarak minimal 3 meter. Selain itu jarak antara sumur resapan dengan pondasi bangunan lainnya seperti rumah atau pagar rumah minimal $1 \mathrm{~m}$ (Badan Standardisasi Nasional, 2002).

Dalam perencanaan drainase, analisis hidrologi merupakan hal yang paling penting yang harus dipertimbangkan, selain kondisi lahan, geologi, jenis tanah serta rembesan permukaan (Sutanto, 2006). Ukuran saluran yang disesuaikan dengan debit aliran air, dimana debit yang dialirkan (Qs) oleh saluran sama atau lebih besar dari debit rencana (Qt) (Wesli, 2008).

Qs = As. V

Dalam Laoh, et al. (2013) dan Arafat (2008), dinyatakan bahwa debit rencana yang didapat diperoleh dari persamaan:

$\mathrm{Qt}=0,00278$. C.I.A

dengan:

As : luas penampang saluran tegak lurus arah aliran $\left(\mathrm{m}^{2}\right)$,

$\mathrm{V}$ : kecepatan rata-rata aliran di dalam saluran ( $\mathrm{m} / \mathrm{det})$,

C : nilai koefisien aliran,

I : intensitas hujan ( $\mathrm{mm} / \mathrm{jam})$,

$$
I=\frac{R_{24}}{24}\left(\frac{24}{t}\right)^{2 / 3}
$$

A : luas daerah aliran $\left(\mathrm{km}^{2}\right)$,

$\mathrm{T}$ : durasi hujan (jam)

Rumus intensitas curah hujan setiap waktu (jam) berdasarkan data curah hujan harian. Jika data hujan yang tersedia dalam tahunan maka perlu diubah dalam bentuk bulanan dan kemudian harian (Fachrurazie, et al., 2002).

\section{METODE PELAKSANAAN}

Lokasi tempat pembuatan model adalah daerah banjir di Desa Lauwonu, Kecamatan Tilango, Kabupaten Gorontalo - Provinsi Gorontalo, tepatnya di Dusun 2 dan Dusun 3. Data yang digunakan adalah data primer dan data sekunder yang diperoleh dari:

a. Data sekunder adalah data yang diperoleh berupa data umum lokasi, topografi dan data kependudukan.

b. Data primer yaitu berupa data lapangan dan data hasil wawancara dengan masyarakat dalam bentuk kuesioner.

Pembuatan model bermaksud untuk memberikan contoh nyata dan pemahaman lebih mendalam bagi para kelompok masyarakat. Untuk dapat mencapai target luaran, maka indikatornya adalah evaluasi pelaksanaan program. Evaluasi dimaksudkan untuk mengetahui tingkat keberhasilan program pengabdian kepada masyarakat yang telah dilaksanakan dan dilakukan setelah kegiatan pengabdian kepada masyarakat ini selesai.

\section{HASIL DAN PEMBAHASAN}

Sumur resapan (Gambar 1) dibuat dengan memanfaatkan material lokal. Air hujan dari atap rumah dialirkan melalui saluran (Gambar 2), sebelum ditampung dalam sumur resapan. Sumur resapan ini dilapisi dengan ijuk sebagai media filter pada sisi-sisi dinding dan dasar sumur dan diurug dengan batu kapur 
(Gambar 3), dengan ukuran $(2 \times 1 \times 1,5)$ $\mathrm{m}^{3}$ (Dusun 2) dan ukuran $(2 \times 1 \times 1) \mathrm{m}^{3}$ (Dusun 3). Pada bagian atas ditutup/dilapisi dengan ijuk dan plastik, yang dilengkapi dengan lubang kontrol atau main hole. Untuk menghindari sampah atau kotoran masuk dalam sumur resapan, maka dibuat bak kontrol dengan diameter $60 \mathrm{~cm}$ (Gambar 4). Air hujan sebelum masuk ke sumur peresapan, harus melalui bak kontrol. Saluran air yang masuk ke bak kontrol dan sumur resapan, menggunakan pipa PVC diameter 3", yang dilengkapi dengan saringan air (floor drain).

Untuk menghindari limpasan air hujan, dari sumur resapan dibuat saluran air limpasan (pipa PVC dia.3") menuju saluran pinggir jalan (riol kota).

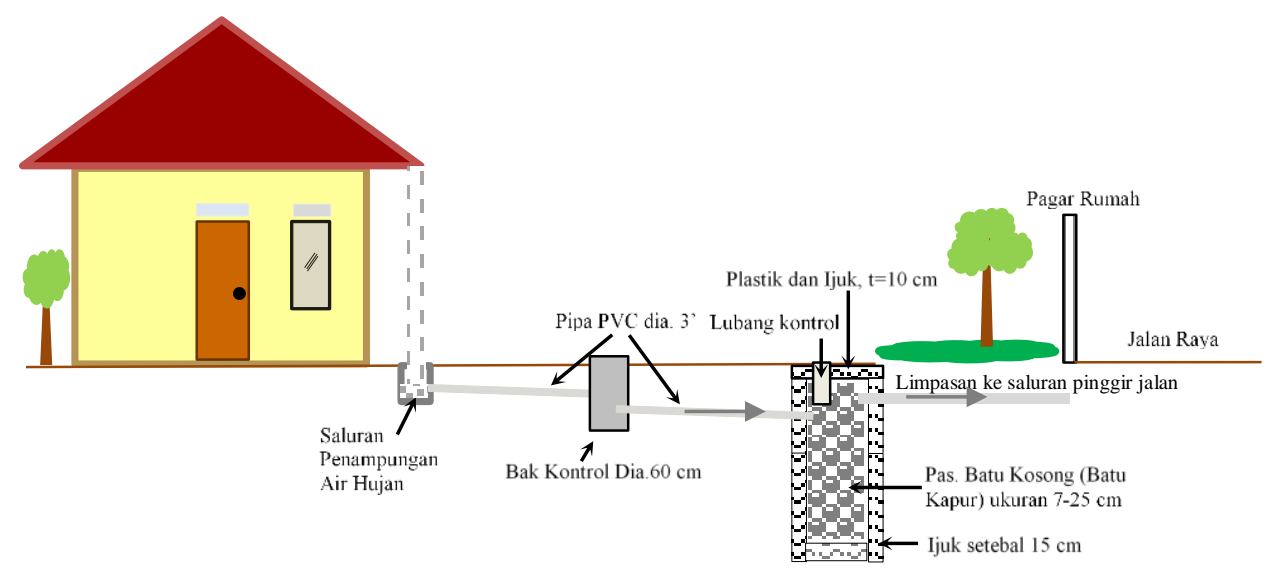

Gambar 1: Model Sumur Resapan Untuk Rumah Tak Bertalang

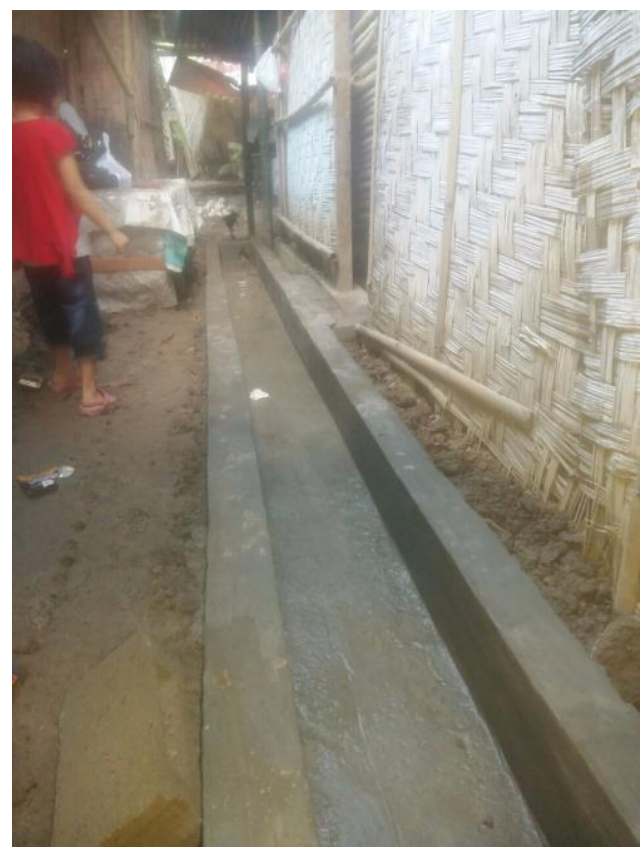

Gambar 2: Saluran Penampungan Air Hujan

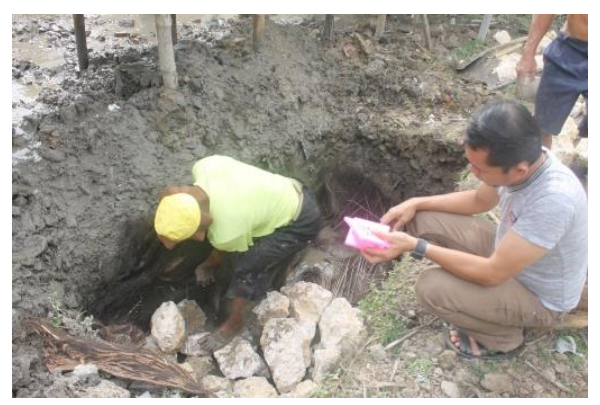

Gambar 3: Sumur Resapan

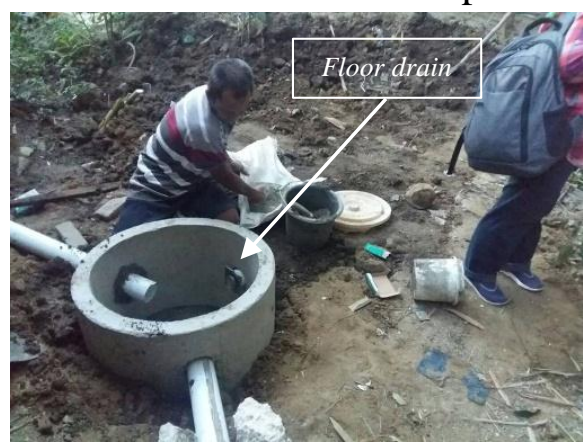

Gambar 4: Bak Kontrol 
Yuliyanti Kadir ${ }^{1}$, Indriati Martha Patuti ${ }^{2}$, Frice L. Desei ${ }^{3}$ /

Aksiologiya: Jurnal Pengabdian Kepada Masyarakat. Vol.1, No.2, Agustus 2017 Hal $92-96$

\section{SIMPULAN}

Adapun yang menjadi

kesimpulan dari penelitian ini adalah:

1. Apabila setiap rumah tangga memiliki 1 buah sumur resapan dengan minimal volume $2 \mathrm{~m}^{3}$, maka akan mengurangi limpasan air hujan, sehingga bencana banjir dapat dihindari.

2. Model sumur resapan dan drainase ini diharapkan menjadi salah satu alternatif dalam pemilihan sumur resapan yang efisien, praktis dan mudah dikerjakan.

3. Penggunaan material lokal sebagai bahan konstruksi sumur resapan, menjadikan biaya yang diperlukan sangat terjangkau.

\section{UCAPAN TERIMAKASIH}

Penulis mengucapkan terima kasih kepada Direktorat Riset dan Pengabdian Masyarakat, Direktorat Jenderal Penguatan Riset dan Pengembangan - Kementerian Riset, Republik Indonesia atas dukungan finansial, menurut kontrak penelitian anggaran 2017 No: 077 / SP2H / LT / DRPM / IV / 2017.

\section{DAFTAR PUSTAKA}

Badan Standardisasi Nasional, 2002. Tata Cara Perencanaan Sumur Resapan Air Hujan untuk Lahan Pekarangan (SNI-03-24532002). Jakarta: BSN.

BPS Kabupaten Gorontalo, 2015. Kecamatan Tilango dalam Angka 2015. Kabupaten Gorontalo: Badan Pusat Statistik Kabupaten Gorontalo.
Dewi, A. K., Setiawan, A. \& Saido, A. P., 2014. Evaluasi Sistem Drainase di Ruas Jalan SoloSragen, Kabupaten Karanganyar. e-Jurnal MATRIKS Teknik Sipil, Maret, II(1), pp. 170-176.

Fachrurazie, C., Arifin, Y. F. \& Susanti, D. S., 2002. Analisa Drainase Sumur Resapan pada Kampus UNLAM Banjarbaru. Info-Teknik, pp. 24-34.

Indramaya, E. A. \& Purnama, I. L. S., 2013. Rancangan Sumur Resapan Air Hujan Sebagai Salah Satu Usaha Konservasi Air Tanah di Perumahan Dayu Baru Kabupaten Sleman Daerah Istimewa Yogyakarta. Jurnal Bumi Indonesia, II(3), pp. 47-54.

Laoh, G. L., Tanudjaja, L., Wuisan, E. \& Tangkudung, H., 2013. Perencanaan Sistem Drainase di Kawasan Pusat Kota Amurang. Jurnal Sipil Statik, April, I(5), pp. 341-349.

Sutanto, 2006. Pedoman Drainase Jalan Raya (American Association of State Highway and Transportation Officials). Jakarta: Universitas Indonesia.

Wahyuningtyas, A., Hariyani, S. \& Sutikno, F. R., 2011. Strategi Penerapan Sumur Resapan Sebagai Teknologi Ekodrainase di Kota Malang (Studi Kasus Sub Das Metro). Jurnal Tata Kota dan Daerah, Juli, III(1), pp. 2531.

Wesli, 2008. Drainase Perkotaan. I ed. Yogyakarta: Graha Ilmu. 